\title{
How Public Works Authority Has Built a Portfolio Dashboard Through Agility Approach
}

\author{
Abdulrahman Mchaweh \\ Amchaweh@Ashghal.gov.qa \\ Public Works Authority (Ashghal), Doha, Qatar
}

\begin{abstract}
The aim of this paper is to share PWA experience to develop a Portfolio Performance Dashboard (PPD) that suits its unique requirements. The case study sheds light on the challenges that PWA faced to develop an interim front reporting solution that deals with multiple scattered reporting systems within the different components of the portfolio. This paper demonstrates how PWA adopted Agility project management to develop a short-term dashboard solution for executive management.
\end{abstract}

Keywords: Dashboard; Reporting; Agility; Business intelligence; Project methodologies

\section{INTRODUCTION}

Agility software development methodology has been gaining interest within software and solutions developers, due to appeal of the agile methodologies to the bureaucracy of the engineering methodologies (Fowler, 2005).

Using Agile methodology in software development depends on several parameters, including project size, level of complexity, integration with other systems, documentation requirements and budget.

One advantage of using the agility method its ability to predict the customer needs, these needs are traditionally collected through business analysis process, which is independent from development phase, However, agility process is iterative that incrementally develops multiple deliveries of ever-growing functionality (Fowler \& Highsmith, 2001; Salah et al., 2014).

PWA in Qatar has been deploying and searching for a PPD for several years, the aim is to have simple, concise, and meaningful information on the status of the portfolio and its major components.

Business intelligence system based on S.A.P was under consideration, but several challenges such as time required designing and implementing, data integration and other issues, called for pragmatic solution that utilizes the available data. Among the options that suite the circumstances were Tableau and Microsoft BI.

\section{PROJECT ASSUMPTIONS}

Various reasons qualified the selection of Tableau, among those is the management previous experience with the solution, the cost of the solution and the ability to fill the gap as to interim solution until organization set "BI Strategy".

Among the advantages of the interim PPD is having overarching solution on top of current "Systems structure" without wholesale change that impacts the ongoing operations, and elimination of many reports to C-level. 
Development team has taken into considerations the organizations structure and data integration level to design a suitable solution that aimed to:

1. Deliver executive management dashboard within 3 months.

2. Work with the departments that have reasonable performance data.

3. Reflect and agree on simple processes that generate information quickly.

4. Standardizations of key information and terminologies.

\section{BUILDING THE PROJECT TEAM}

PWA senior management tasked the corporate Project Management Office (PMO) to lead the project development in collaboration with Information technology department to support aspects such as, application Licenses and Dashboard developers.

The selection criteria that qualifies Tableau to build PPD is:

1. Application license is affordable.

2. The solution is applicable to link to several databases such as Excel and Oracle Tableau.

3. Tableau Reader Application for end users is free and could be installed on standard systems in PWA.

4. Intuitive and rich user interface.

5. Previous management experience with the solution.

6. Tableau dashboard to serve as an interim solution.

The core development team consists of planning engineers; project advisor and one Tableau developer. The initial requirements are collected through workshops with senior and middle management; all draft designs were demonstrated using power point slides to effectively communicate initial thoughts without investing time and effort in building modules using sophisticated dashboard solution.

Due to lack of centralized portfolio database that includes program data, commercial aspects and quality parameters, Excel is the most pragmatic tool collect data. The spreadsheets include performance and commercial data in addition to high-level risk, quality and procurement information; however, data collection and data quality remain the key challenges for the project team.

Additionally, the rigid organization structure is a key aspect to important parameters consider in building PPD. The reporting function was assigned to a particular business unit while the information technology department is mandated to deliver (software solutions) irrespective of the projected environment of the organization.

\section{PROJECT MANAGEMENT APPROACH TO DELIVER THE SOLUTION}

The team lead set a clear plan to deliver the solution to meet tight time constraints using agility process where:

1. Each deliverable was managed as an independent project.

2. User testing process was done during the development phase, the feedbacks and challenges are used as a lesson learned for further development.

3. Started with of 5 Tableau desktop licenses and more added as the development proceeds.

4. Build standards and definitions template and get data owner's buy-in.

5. Assign focal points within the departments to manage data collection, data quality and data acceptance processes. 
6. Build data collection templates, a complete workbook is designed, it contained 17 sheets to collect all data sets from different departments.

7. Daily review meeting to review project progress and assign tasks. All tasks managed internally using a shared task list.

8. Adding value to current reports, through linking GIS (data to identify project locations.

\section{CHALLENGES DURING THE PLANNING AND IMPLEMENTATION PHASES}

Over the project lifecycle, several challenges were identified. Some are unique and related to the organization data 'structure, others are common in fast delivery software projects. Among those are:

1. The developers usually do not understand construction jargons; this creates barriers between the developer and the users.

2. Challenging timeframes to deliver the dashboards solution to management.

3. Bringing the internal departments to speed, arrangements were needed to develop new data sets, agree on definitions, standards, user acceptance and delivery dates.

4. Continuous collaboration and coordination between IT department and reporting team to deliver the solution to the satisfaction of senior management.

5. New requirements, new schemes, new initiatives and new stakeholders.

\section{RESULTS}

The team was able to deliver the PPD within 3 months and obtain management approval on the final dashboard. During the following year, more than 10 dashboards were developed for highway projects, local roads projects, drainage projects and building departments

The departments showed interest in Tableau, several departments requested to use dashboard to replace current reports and get advantages of rich graphical interface and the ability to connect to several data sources.

The lessons learned from each dashboard used as an input to improve next release of the dashboard and management team was able to augment the knowledge needed to link data sources and capture results.

Senior management and Information technology department considered Tableau as one of the potential solutions to include as a part of the Business intelligence strategy.

\section{CONCLUSION}

Agility process is gaining interest in software development mainly for fast track projects that have limited resources. This process motivate the teams and provide high learning in addition to its clear advantage in controlling the final product specifications.

However, managing project teams, scope creep and lack of clear business requirements are main obstacles to develop powerful PPD, furthermore, Management support of is key for the success those initiatives.

\section{REFERENCES}

Fowler, M. (2005). The new methodology. Software. World, Vol. 36, No. 1, pp. 3-6. 
Fowler, M. \& Highsmith, J. (2001). The agile manifesto, pages 3.

Salah, D., Paige, R. F. \& Cairns, P. (2014). A systematic literature review for Agile development processes and user centered design integration. ACM Int. Conf. Proceeding Ser., No. May 2014. 